\title{
Does associative LTP underlie classical conditioning?
}

\author{
DAVID M. DIAMOND and GREGORY M. ROSE \\ University of Colorado Health Sciences Center, Denver, Colorado \\ and Veterans Affairs Medical Center, Denver, Colorado
}

\begin{abstract}
A major goal in cognitive neuroscience is to identify the cellular substrates that underlie learning and memory. One prominent approach toward achieving this goal has been to study the enhancement of synaptic transmission produced by high-frequency electrical stimulation. This activity-dependent increase in synaptic strength, which shares characteristics with memory, is commonly referred to as long-term potentiation (LTP). One focus within the LTP field is a phenomenon termed "associative LTP." Associative LTP is an enhancement of response that develops specifically as a result of the coactivation of two anatomically distinct inputs. Some investigators have suggested that associative LTP is a substrate for classical conditioning, based on the apparent correspondence between the parameters of electrical stimulation used to induce associative LTP and the parameters of training used in classical conditioning. This commentary presents our view that the notion of a putative associative LTP/classical conditioning connection is of limited heuristic value. We have proposed an alternative interpretation of the findings based on the hypothesis that an associative LTP-like process occurs during behavioral conditions that produce intense coactivation of different groups of hippocampal synapses. Endogenous associative LTP might occur as a result of the synchronous activation of the hippocampus by rhythmic bursting activity (theta rhythm) and afferent activity conveying information about the animal's environment. This approach minimizes fitting models of learning to the temporal constraints of classical conditioning training parameters and emphasizes an understanding of the behavioral conditions that maximize synaptic plasticity and information storage.
\end{abstract}

For over two decades, long-term potentiation (LTP) has been the most widely studied electrophysiological model of memory. LTP is an electrically stimulated enhancement of synaptic efficacy that shares characteristics with memory (Bliss, 1990; Lynch, Kessler, Arai, \& Larson, 1990; Madison \& Schuman, 1991; Teyler \& DiScenna, 1987). A primary issue in the field, which has yet to be resolved, is if LTP is a substrate for memory (Berger, 1984; Bliss \& Richter-Levin, 1993; Castro, Silbert, McNaughton, \& Barnes, 1989; McNaughton, Barnes, Rao, Baldwin, \& Rasmussen, 1986). The issue is further complicated by the suggestion that one form of LTP, which has been referred to as "associative LTP," is a sub-

The authors were supported by grants from the Veterans Affairs Medical Research Service (to D.M.D. and G.M.R.), NIA Grant AG10755 (to G.M.R.), and the Office of Naval Research Grant ONR N00014-91-J-1753 (to D.M.D.) during the preparation of this commentary. We thank Kevin Austin and Tom Dunwiddie for their comments on this work. We also appreciate the constructive criticisms provided by the reviewers of this manuscript. Both authors are affiliated with the Department of Pharmacology at the University of Colorado Health Sciences Center and with the Medical Research Service at the Veterans Affairs Medical Center, Denver. G.M.R. is also affiliated with the Neurosciences Training Program at the University of Colorado Health Sciences Center. Correspondence should be addressed to D. M. Diamond, Department of Pharmacology, Box C236, University of Colorado Health Sciences Center, Denver, CO 80262 (e-mail: diamondd@essex.hsc.colorado.edu). strate for classical conditioning (Kelso \& Brown, 1986; Kelso, Ganong, \& Brown, 1986). The linkage of associative LTP to associative learning has become so commonly stated in the literature that it appears to have been accepted without debate (e.g., Abraham, 1988; Buonomano \& Byrne, 1990; Fanselow, 1993; Kitajima \& Hara, 1991; Levy \& Steward, 1979; Teyler \& DiScenna, 1987; Young, Bohenek, \& Fanselow, 1994). We believe that there are flaws in this extrapolation from synaptic plasticity to associative learning from both physiological and cognitive perspectives. Our primary goal in this commentary is to assess the hypothesis that associative LTP is a substrate of classical conditioning. Our point of view is that a rigorous analysis of the associative LTP paradigm reveals only a coincidental resemblance to classical conditioning. We propose an alternative hypothesis in which the relevance of the associative LTP findings to hippocampal function is considered in a broader behavioral context, which encompasses, but is not restricted to, classical conditioning.

\section{Definition of Terms}

Historically, classical conditioning was based on the view that learning is an association that is made between two stimuli presented in close temporal proximity. Specifically, one initially neutral stimulus, such as a sound (conditioned stimulus, or CS), is paired with a motivationally strong stimulus, such as food or shock (uncon- 
ditioned stimulus, or US), which consistently evokes a response. As a result of the pairing of the CS with the US, the CS comes to evoke a conditioned or learned response (CR); in the case of Pavlov's work with dogs, the pairing of the sound of a bell (CS) with food (US) resulted in the sound alone evoking salivation (CR; see Pavlov, 1928).

The associative LTP paradigm has its foundation in the work of Levy and Steward (1979), who introduced a novel methodological approach to generate LTP. These authors demonstrated that LTP could be induced by the conjoint activity of anatomically distinct inputs. They suggested that the combinatorial aspect of the induction of LTP was consistent with theoretical work on the formation of associative memory (Hebb, 1949). The essence of the associative LTP methodology is the following: High-frequency stimulation of one input with low-intensity (weak) current is ineffective in inducing LTP. However, if the weak input is stimulated at the same time as a second strong input, then LTP will occur at the weak input (Auyeung, May, Goh, \& Sastry, 1987; Brown, Kairiss, \& Keenan, 1990; Kelso \& Brown, 1986; Sastry, Goh, \& Auyeung, 1986). The dependence of the development of LTP on the necessary pairing of two (weak and strong) inputs led to the conception of LTP as an associative process (Levy \& Steward, 1979). This view of associativity was consistent with the definition of learning as the result of the pairing of two stimuli and the production of a response.

In the years since associative LTP was conceived, investigators have employed successive degrees of reductionism in an attempt to relate associative LTP to associative learning. An ambitious effort in this direction was put forth by Kelso and Brown (1986), who employed an electrical stimulation procedure that mimicked the methodology used in classical conditioning training. The apparent correspondence between the characteristics of associative LTP and classical (or Pavlovian) conditioning led to their suggestion that "the mechanism responsible for (associative LTP) participates in some aspect of the suspected role of (the hippocampus) in higher order Pavlovian conditioning" (Kelso \& Brown, 1986, p. 86).

\section{Associative LTP is Not a Unique Model of Learning}

The general characteristics of the physiology of NMDA-mediated LTP have been well studied. Briefly, afferent activity produces a presynaptic release of amino acids (glutamate/aspartate) that depolarize postsynaptic sites. This depolarization removes a voltage-dependent magnesium block within the NMDA channel. With continued depolarization, the NMDA channel remains open, allowing $\mathrm{Ca}^{++}$ions to enter the cell and trigger a biochemical cascade that can eventually result in an enhancement of synaptic transmission (Colley \& Routtenberg, 1993; Collingridge, 1992; Collingridge \& Bliss, 1987; Lynch \& Baudry, 1987; Teyler, 1991).
Given the advances in understanding the sequence of events involved in the induction of LTP, we can consider where associative LTP fits in this schema. Proponents of the associative LTP/classical conditioning concept stated that the purpose of the strong input in associative LTP is "simply to supply a critical amount of post-synaptic depolarization" in conjunction with stimulation of the weak input (Kelso et al., 1986, p. 5329). The strong depolarization source may be produced by afferent activity (Kelso \& Brown, 1986) or by direct intracellular current injection (Gustafsson, Wigström, Abraham, \& Huang, 1987; Kelso et al., 1986). This observation indicates, therefore, that the basis for the induction of associative LTP is that simultaneous stimulation of the two inputs produces a sufficient amount of postsynaptic excitability in the weak input to exceed a local depolarization threshold. ${ }^{1}$

Associative LTP is similar to a phenomenon that has been referred to as "cooperativity." The primary emphasis of cooperativity is that there needs to be a sufficiently large number of afferent fibers activated to induce LTP (Brown et al., 1990; McNaughton, Douglas, \& Goddard, 1978). Whereas cooperativity can be demonstrated with stimulation of a single input (a "nonassociative" stimulation paradigm), associativity involves the simultaneous stimulation of two different inputs. Although associative LTP and cooperativity differ in terms of the anatomical distribution of presynaptic activity, they share the common requirement that a localized, synapsespecific, postsynaptic depolarization threshold must be exceeded to induce LTP (Andersen, 1991; Brown et al., 1990; Colbert \& Levy, 1993; Gustafsson \& Wigström, 1986; Teyler \& DiScenna, 1987). The induction of LTP in hippocampal area CA1 is independent of whether stimulation of two afferents summate and exceed the threshold (associativity) or whether a single input, alone or in conjunction with depolarizing current injection, exceeds the threshold (nonassociativity or cooperativity) (Andersen, 1991; Gustafsson \& Wigström, 1986; Gustafsson et al., 1987). Associative LTP, therefore, is unique only in terms of its stimulation parameters and presynaptic activity; the resultant postsynaptic plasticity is independent of whether an associative or nonassociative stimulation paradigm was employed.

The associative LTP protocol is a methodological approach that employs two sources of afferent stimulation to increase the amount of postsynaptic depolarization so as to produce plasticity. From this perspective, it seems difficult to accept the assertion that associative LTP "could mediate aspects of associative learning" (Kelso \& Brown, 1986). On the basis of this logic, it is equally reasonable to propose that LTP could mediate aspects of other forms of learning. For example, repeated stimulation of a single input (homosynaptic LTP) could mediate a nonassociative form of learning, such as habituation. Alternatively, associative LTP may underlie sensory preconditioning - that is, associating one CS (a light) with another CS (a sound) (Port, Beggs, \& Patterson, 1987). However, grasping at analogies between electri- 
cal stimulation parameters and training parameters in different forms of learning would seem to us to be of questionable heuristic value. The electrical stimulation parameters that induce LTP may bear a superficial resemblance to the training parameters employed in classical conditioning (or habituation/sensory preconditioning), but the two may have little of functional significance in common.

Findings from a broad range of methodological approaches have supported the general hypothesis that an LTP-like phenomenon is involved in memory formation. However, to extend this global hypothesis to the specific notion that an LTP-like process could mediate higher forms of Pavlovian conditioning seems unjustified. Our understanding of the possible role of LTP in learning is still embryonic. At the most fundamental level, LTP is a model of memory because it is a change in cellular excitability that outlasts a brief period of stimulation. How LTP is involved in specific forms of learning, if at all, remains to be determined.

\section{Associative LTP Does Not Model Contemporary Views of Classical Conditioning}

According to some investigators, associative LTP shares formal features with classical conditioning (Abraham, 1988; Kelso \& Brown, 1986) and is "reminiscent of Pavlovian conditioning" (Kelso et al., 1986). More recently, Fanselow (1993) reviewed the associative LTP literature and concluded that "LTP has an associative nature, and the analogy to Pavlovian conditioning is clear." Thus, one implication in the associative LTP paradigm is that stimulation of the weak and strong inputs is analogous to presentation of the CS and US in classical conditioning (Levy \& Steward, 1979). To explore this notion in depth, we will consider how the parameters of associative LTP map onto the parameters of classical conditioning.

From a behavioral perspective, associative LTP as a possible basis of classical conditioning is flawed because it does not take into account contemporary accounts of the cognitive capacity of animals. The dependence of associative LTP on the fixed timing of the pairing of two stimuli is reminiscent of more traditional, and now antiquated, views of classical conditioning. Rescorla (1988a) has provided a current perspective on an appreciation of the dynamics of associative learning. He stated that

The (traditional) descriptions of (Pavlovian) conditioning ... imply a highly restricted content in which a single neutral stimulus becomes associated with one that evokes a response. But modern Pavlovian thinking suggests a picture that is richer ... the simple pairing of two events cannot be taken as fundamental to the description of Pavlovian conditioning. Instead, ... the prevalent modern view is that conditioning involves the learning of relations among events. (Rescorla, 1988a, pp. 153, 155)

In a similar view of animal learning, Dickinson (1980) proposed that "learning must consist of setting some form of internal representation of the relationship which exists between events in the animal's environment" (p. 22). These conclusions are based on decades of research that have demonstrated that a broad range of CS-US delays will support learning, that CS-CS associations can be formed in the absence of a US, and that many different $\mathrm{CRs}$ are generated during classical conditioning (Dickinson, 1980; Hilgard \& Marquis, 1961; Lennartz \& Weinberger, 1992; Rescorla, 1988a). A comprehensive theory of the relevance of LTP to learning should take into account the contemporary view that animals learn the temporal and spatial relationships among stimuli in their environment.

From a methodological perspective, the parameters for the induction of associative LTP differ substantially from those of classical conditioning. For example, maximal associative LTP develops when the weak and strong stimuli are delivered simultaneously. The longest "trace" period-that is, the delay between the offset of the weak stimulus and the onset of the strong stimulusis about $40 \mathrm{msec}$ (Auyeung et al., 1987; Gustafsson \& Wigström, 1986; Levy \& Steward, 1983; Wigström \& Gustafsson, 1986). Simultaneous presentation of a CS and US may produce learning in some circumstances, but it is well established that this approach is largely an ineffective method for producing optimal behavioral learning (Dickinson, 1980; Hartman \& Grant, 1962; Rescorla, 1988a, 1988b). The mismatch between optimal CS-US intervals in classical conditioning and the optimal weak/strong electrical stimulation parameters in associative LTP has been mentioned by some investigators (Abrams \& Kandel, 1988; Diamond, Dunwiddie, \& Rose, 1988; Levy \& Steward, 1983) and was considered at length by Abraham (1988), who commented that associative LTP does not show "the same optimal interstimulus intervals (e.g., as in classical conditioning) that are prominent features of associative learning." However, this issue was not considered crucial because "LTP is studied within the confines of a simple model system, and it would be rather surprising if all behavioural features were present in the model. One expects that activity within other relevant brain circuits, and its timing within these circuits, will determine many of the animal's learning characteristics" (Abraham, 1988, p. 53).

That the activity of a simple model system cannot precisely mimic complex behaviors is an important caveat to consider in critiquing the putative associative LTP/ classical conditioning connection. However, the problem remains that aside from the observation that two stimuli combine to produce a lasting effect, associative LTP and classical conditioning have little of consequence in common. For example, associative LTP can be induced when stimulation of the strong input precedes the weak input-that is, US stimulation precedes the CS (Auyeung et al., 1987; Gustafsson \& Wigström, 1986; Wigström \& Gustafsson, 1986). Although this electrical stimulation paradigm is effective in inducing LTP, it models backward conditioning, which is ineffective in producing behavioral learning (Dickinson, 1980; Kimble, 1967; Rescorla, 1988a). Furthermore, associative 
LTP stimulation can produce an enhancement in transmission at both the weak and the strong inputs (Brown et al., 1990). This observation would suggest that classical conditioning should produce an enhancement of behavioral response to both the CS and the US. However, during classical conditioning, there is a change in response to the CS, but there is no significant change in response to the US (Kimble, 1967; Pavlov, 1928).

An additional problem in attempting to relate associative LTP in the hippocampus to classical conditioning is that there are different forms of classical conditioning, including those that can develop in animals that have hippocampal damage (Moyer, Deyo, \& Disterhoft, 1990; O'Keefe \& Nadel, 1978; Solomon, Vander Schaaf, Thompon, \& Weisz, 1986). We assert that associative LTP is neither a general model of classical conditioning nor a specific model of forms of classical conditioning that are dependent on the functional integrity of the hippocampus.

Although we consider the attempt to make a direct connection between associative LTP and classical conditioning to be of limited utility, the issue remains as to how an associative LTP-like process might be involved in learning. One approach toward resolving this issue is that the combinatorial aspect of associative LTP indicates that information is processed by a network of neurons in the hippocampus, which is maximally sensitive to the synchronous activation of its inputs. Given the anatomical distance of the hippocampus from primary sensory and motor structures, the convergence of information in the hippocampus may not need to be timelocked to onset of the CS and US. If the relevance of associative LTP to learning can be expanded beyond the temporal confines of classical conditioning methodology, we can explore the broader question of how endogenous forms of hippocampal plasticity may develop as animals interact with their environment. Associative LTP, when viewed as a process by which plasticity is produced at a reduced threshold, may provide insight into the more general question of how the hippocampus stores information. In the next section, we consider an alternative application of the possible involvement of associative LTP in hippocampal-dependent learning.

\section{Associative LTP, the Hebb Synapse, and Hippocampal-Dependent Learning}

Associative LTP has been proposed to be the physiological manifestation of the "Hebb synapse" (Brown et al., 1990; Kelso et al., 1986; Stanton \& Sejnowski, 1989; Zador, Koch, \& Brown, 1990). The original idea proposed by Hebb (1949) was the following: "When an axon of cell $A$ is near enough to excite cell $B$ or repeatedly or persistently takes part in firing it, some growth process or metabolic change takes place in one or both cells such that A's efficiency, as one of the cells firing B, is increased" (p. 62). A contemporary interpretation of this hypothesis is that synchronous activation of two neurons, involving both pre- and postsynaptic excitation, will strengthen the connectivity between them.
Ironically, a viable application of Hebb's ideas to LTP and memory has been studied by investigators who have not embraced the associative LTP paradigm. Work initiated by Larson and Lynch (1986) and Rose and Dunwiddie (1986) provided a novel approach to the induction of LTP. These investigators induced LTP using a pattern of electrical pulses based on the temporal parameters of the endogenous rhythms (the $5-8-\mathrm{Hz}$ theta rhythm) that occur in the hippocampus of behaving animals (Bland, 1986; Vanderwolf, 1969). Unlike the long continuous trains of pulses that had been used prior to these studies (e.g., 100 pulses for $1 \mathrm{sec}$ ), theta stimulation is composed of brief high-frequency bursts (4-10 pulses at $200 \mathrm{~Hz}$ ) delivered at 170-200-msec intervals. These and later studies (Diamond et al., 1988; Greenstein, Pavlides, \& Winson, 1988; Pavlides, Greenstein, Grudman, \& Winson, 1988) demonstrated that the threshold for the induction of LTP in both CA1 and the dentate gyrus is dramatically lower with theta patterned stimulation than with nonpatterned (continuous) trains of pulses. In recent years, the theta-stimulation approach to LTP has provided insights into the behavioral (Diamond, Bennett, Stevens, Wilson, \& Rose, 1990; Diamond, Fleshner, \& Rose, 1994; Leung, Shen, \& Kaibara, 1992; Shors \& Thompson, 1992; Staubli \& Lynch, 1987), pharmacological (Corradetti, Bellerini, Pugliese, \& Pepen, 1992; Diamond, Bennett, Fleshner, \& Rose, 1992; Larson \& Lynch, 1988; Pacelli, Su, \& Kelso, 1992; Staubli \& Otaky, 1994), and age-related (Moore, Browning, \& Rose, 1993) modulation of hippocampal plasticity.

The discovery of physiologically patterned stimulation as an effective means to initiate synaptic plasticity was based on the general hypothesis that endogenous rhythms facilitate information encoding in the hippocampus. Theta-stimulation-induced LTP may occur in the behaving animal as a two-component form of plasticity, which conforms to the concept of the Hebb synapse. One component of Hebbian plasticity is the theta rhythm. In theory, as animals explore their environment the highfrequency bursts of cell activity occurring approximately every $170-200 \mathrm{msec}$ (theta rhythm) could produce sufficient depolarization to briefly open NMDA channels (Pacelli, Su, \& Kelso, 1991). The theta rhythm alone would not produce plasticity, but it would prime the synapses to be more receptive to generating plasticity. A second component of Hebbian plasticity would be the activation of the hippocampus by afferent activity conveying information about the subject's environment. Simultaneous activation of hippocampal synapses by theta bursting and sensory stimulation could engage mechanisms of information storage. This hypothesis is an extension of previous considerations of the functional significance of theta-related plasticity (Diamond et al., 1988; Gluck \& Granger, 1993; Huerta \& Lisman, 1993; Larson \& Lynch, 1986, 1989; Lynch, Granger, \& Staubli, 1991; Pacelli et al., 1989), and the suggestion by Vertes (1986) that "information arriving simultaneously with 
theta may have a greater access to hippocampal circuitry that may result in the long-term storage of that information" (p. 66).

The associative LTP work indicates that subthreshold inputs can be potentiated if they are activated simultaneously with strong secondary inputs. Perhaps the relevance of the associative LTP phenomenon to learning is that plasticity of weak inputs will be more likely to occur if there is a correlation between the timing of the theta rhythm and afferent activity. Empirical support for this hypothesis is derived from studies that indicate that an interaction between theta and secondary afferent activity enhances physiological activity. For example, the amplitudes of evoked potentials (Rudell, Fox, \& Ranck, 1980; Winson \& Abzug, 1977, 1978) and LTP (Bramham, Maho, \& Laroche, 1994; Bramham \& Srebro, 1989; Greenstein et al., 1988; Pavlides et al., 1988) were altered when the electrical stimulation occurred during theta activity. More specifically, Huerta and Lisman (1993) and Pavlides et al. (1988) investigated the relationship between coincident activation of the hippocampus by highfrequency electrical stimulation and theta activity. These authors demonstrated that the magnitude of LTP was maximal when electrical stimulation was synchronized with the positive phase of the theta rhythm. The associative LTP paradigm may have inadvertently explored the temporal constraints on the optimal timing for the convergence of the positive phase of the theta rhythm with afferent excitation from a secondary source. That is, maximum plasticity may occur when afferent excitation occurs within $40 \mathrm{msec}$ of the peak of the positive phase of the theta rhythm (Gustafsson \& Wigström, 1986; Levy \& Steward, 1983). ${ }^{2}$

The coincidental activation of the hippocampus by the theta rhythm and afferent activity may encompass, but is not restricted to, classical conditioning. Moreover, this approach may be useful in addressing certain forms of hippocampal-dependent learning, such as spatial and contextual learning, which do not conform to the temporal constraints of CS-US intervals inherent in classical conditioning training. This view of the possible involvement of associative LTP in hippocampal function may provide a framework for identifying the circumstances that maximize behavioral adaptation and electrophysiological plasticity.

\section{Conclusions}

Our primary goal has been to assess the utility of the associative LTP paradigm as a physiological model of associative learning. We have presented the view that stimulation of two inputs that summate to produce LTP is not a satisfactory model of learning, within the restrictive context of classical conditioning training parameters. The issue remains, however, as to the significance of the associative LTP phenomenon. We have suggested that the associative LTP findings can be incorporated into recent work identifying the sensitivity of hippocampal plasticity to the timing of the theta rhythm. Concurrent activation of hippocampal synapses by theta bursting and spatial information may produce synaptic plasticity and maximize information storage. The idea that endogenous rhythms regulate plasticity in the hippocampus is not an attempt at modeling learning within the methodological constraints of any experimental paradigm, such as classical conditioning. Instead, the approach may facilitate progress toward understanding the more general issue of how the hippocampus is involved in the acquisition and storage of information.

\section{REFERENCES}

Abraham, W. C. (1988). Long-term potentiation as a possible associative memory mechanism in the brain. New Zealand Journal of Psychology, 17, 49-58.

Abrams, T. W., \& Kandel, E. R. (1988). Is contiguity detection in classical conditioning a system or a cellular property? Learning in aplysia suggests a possible molecular site. Trends in Neurosciences, 11, 128-135.

Ahissar, E., Vaadia, E., Ahissar, M., Bergman, H., Arieli, A., \& ABELES, M. (1992). Dependence of cortical plasticity on correlated activity of single neurons and on behavioral context. Science, 257, 1412-1415.

ANDERSEN, P. (1991). Parameters controlling the induction of longterm potentiation. In W. C. Abraham, M. Coballis, \& K. G. White (Eds.), Memory mechanisms: A tribute to G. V. Goddard (pp. 47-57). Hillsdale, NJ: Erlbaum.

ARTOla, A., \& Singer, W. (1993). Long-term depression of excitatory synaptic transmission and its relationship to long-term potentiation. Trends in Neurosciences, 16, 480-487.

Auyeung, A., May, P. B., Goh, J. W., \& Sastry, B. R. (1987). Temporal requirements of associative short-term potentiation in CA1 neurons of rat hippocampus. Neuroscience Letters, 79, 117-122.

BERGER, T. W. (1984). Long-term potentiation of hippocampal synaptic transmission affects rate of behavioral learning. Science, 224, 627-630.

BLAND, B. H. (1986). The physiology and pharmacology of hippocampal formation theta rhythms. Progress in Neurobiology, 26, 1-54.

BLIss, T. V. P. (1990). Long-term potentiation. Science, 249, 973.

Bliss, T. V. P., \& Richter-Levin, G. (1993). Spatial learning and the saturation of long-term potentiation. Hippocampus, 3, 123-126.

Bramham, C. R., Maho, C., \& Laroche, S. (1994). Suppression of long-term potentiation induction during alert wakefulness but not during "enhanced" REM sleep after avoidance learning. Neuroscience, 59, 501-509.

Bramham, C. R., \& SRebro, B. (1989). Synaptic plasticity in the hippocampus is modulated by behavioral state. Brain Research, 493, 74-86.

Brown, T. H., Kairiss, E. W., \& Keenan, C. L. (1990). Hebbian synapses: Biophysical mechanisms and algorithms. Annual Review of Neuroscience, 13, 475-511.

Buonomano, D. V., \& Byrne, J. H. (1990). Long-term synaptic changes produced by a cellular analog of classical conditioning in aplysia. Science, 249, 420-423.

BUZSAKI, G. (1989). Two-stage model of memory trace formation: A role for "noisy" brain states. Neuroscience, 31, 551-570.

Buzsaki, G., Chen, L. S., \& GaGE, F. H. (1990). Spatial organization of physiological activity in the hippocampal region: Relevance to memory formation. In J. Storm-Mathisen, J. Zimmer, \& O. P. Ottersen (Eds.), Progress in brain research: Vol. 83. Understanding the brain through the hippocampus (pp. 257-268). Amsterdam: Elsevier.

Castro, C. A., Sil bert, L. H., McNaughton, B. L., \& Barnes, C. A. (1989). Recovery of spatial learning deficits after decay of electrically induced synaptic enhancement in the hippocampus. Nature, 342, 545-548.

Colbert, C. M., \& Levy, W. B. (1993). Long-term potentiation of perforant path synapses in hippocampal CAl in vitro. Brain Research, 606, 87-91.

Colley, P. A., \& Routtenberg, A. (1993). Long-term potentiation as synaptic dialogue. Brain Research Reviews, 18, 115-122. 
Collingridge, G. L. (1992). The mechanism of induction of NMDA receptor-dependent long-term potentiation in the hippocampus. Experimental Physiology, 77, 771-797.

CollingRidge, G. L., \& Bliss, T. V. P. (1987). NMDA receptors: Their role in long-term potentiation. Trends in Neurosciences, 10, 288-293.

Corradetti, R., Ballerini, L., Pugliese, A. M., \& Pepeu, G. (1992). Serotonin blocks the long-term potentiation induced by primed burst stimulation in the CAl region of rat hippocampal slices. Neuroscience, 46, 511-518.

Diamond, D. M., Bennett, M. C., Fleshner, M., \& Rose, G. M. (1992). Inverted-U relationship between the level of peripheral corticosterone and the magnitude of hippocampal primed burst potentiation. Hippocampus, 2, 421-430.

Diamond, D. M., Bennett, M. C., Stevens, K. E., Wilson, R. L., \& Rose, G. M. (1990). Exposure to a novel environment interferes with the induction of hippocampal primed burst potentiation. Psychobiology, 18, 273-281.

Diamond, D. M., Dunwiddie, T. V., \& Rose, G. M. (1988). Characteristics of hippocampal primed burst potentiation in vitro and in the awake rat. Journal of Neuroscience, 8, 4079-4088.

Diamond, D. M., Fleshner, M., \& Rose, G. M. (1994). Psychological stress repeatedly blocks hippocampal primed burst potentiation in behaving rats. Behavioural Brain Research, 62, 1-9.

DiCKINSON, A. (1980). Contemporary animal learning theory. Cambridge: Cambridge University Press.

FANSELOW, M. S. (1993). Associations and memories: The role of NMDA receptors and long-term potentiation. Current Directions in Psychological Science, 2, 152-156.

Fregnac, Y., Shulz, D., Thorpe, S., \& Bienenstock, E. (1992). Cellular analogs of visual cortical epigenesis: 1 . Plasticity of orientation selectivity. Journal of Neuroscience, 12, 1280-1300.

Gluck, M. A., \& Granger, R. (1993). Computational models of the neural bases of learning and memory. Annual Review of Neuroscience, 16, 667-706.

Greenstein, Y. J., Pavlides, C., \& Winson, J. (1988). Long-term potentiation in the dentate gyrus is preferentially induced at theta rhythm periodicity. Brain Research, 438, 331-334.

GustafsSon, B., \& Wigström, H. (1986). Hippocampal long-lasting potentiation produced by pairing single volleys and brief conditioning tetani evoked in separate afferents. Journal of Neuroscience, $\mathbf{6}$, 1575-1582.

Gustafsson, B., Wigström, H., Abraham, W. C., \& Huang, Y. Y. (1987). Long-term potentiation in the hippocampus using depolarizing current pulses as the conditioning stimulus to single volley synaptic potentials. Journal of Neuroscience, 7, 774-780.

Hartman, T. F., \& GRanT, D. A. (1962). Differential eyelid conditioning as a function of the CS-US interval. Journal of Experimental Psychology, 64, 131-136.

HEBB, D. O. (1949). The organization of behavior. New York: Wiley.

HILGARD, E. R., \& MARQUis, D. G. (1961). Conditioning and learning New York: Appleton-Century-Crofts.

Huerta, P. T., \& Lisman, J. E. (1993). Heightened synaptic plasticity of hippocampal CA1 neurons during a cholinergically induced rhythmic state. Nature, 364, 723-725.

KELSO, S. R., \& BROWN, T. H. (1986). Differential conditioning of associative synaptic enhancement in hippocampal brain slices. Science, 232, 85-87.

Kelso, S. R., Ganong, A. H., \& Brown, T. H. (1986). Hebbian synapses in hippocampus. Proceedings of the National Academy of Sciences of the United States of America, 83, 5326-5330.

KIMBLE, G. A. (1967). Foundations of conditioning and learning. New York: Appletion-Century-Crofts.

Kitajima, T., \& HARA, K. (1991). A model of the mechanism of cooperativity and associativity of long-term potentiation in the hippocampus: A fundamental mechanism of associative memory and learning. Biological Cybernetics, 64, 365-371.

LARSON, J., \& LYNCH, G. (1986). Induction of synaptic potentiation in hippocampus by patterned stimulation involves two events. Science, 232, 985-988.

LARSON, J., \& LYNCH, G. (1988). Role of N-methyl-D-aspartate receptors in the induction of synaptic potentiation by burst stimulation patterned after the hippocampal theta-rhythm. Brain Research, 441, 111-118.

LARSON, J., \& LYNCH, G. (1989). Theta pattern stimulation and the induction of LTP: The sequence in which synapses are stimulated determines the degree to which they potentiate. Brain Research, 489 , 49-58.

LenNartz, R. C., \& Weinberger, N. M. (1992). Analysis of response systems in Pavlovian conditioning reveals rapidly versus slowly acquired conditioned responses: Support for two factors, implications for behavior and neurobiology. Psychobiology, 20, 93-119.

LeUng, L. S., Shen, B., \& Kaibara, T. (1992). Long-term potentiation induced by patterned stimulation of the commissural pathway to hippocampal CAl region in freely moving rats. Neuroscience, $\mathbf{4 8}$, 63-74.

LEVY, W. B., \& STEWARD, O. (1979). Synapses as associative memory elements in the hippocampal formation. Brain Research, 175, 233-245.

LEVY, W. B., \& STEWARD, O. (1983). Temporal contiguity requirements for long-term associative potentiation/depression in the hippocampus. Neuroscience, 8, 791-797.

LYNCH, G., \& BAUDRY, M. (1987). Brain spectrin, calpain and long-term changes in synaptic efficacy. Brain Research Bulletin, 18, 809-815.

LyNCH, G., GRANGer, R., \& STAUBLI, U. (1991). Long-term potentiation and the structure of memory. In W. C. Abraham, M. Coballis, $\&$ K. G. White (Eds.), Memory mechanisms: A tribute to G. V. Goddard (pp. 3-26). Hillsdale, NJ: Erlbaum.

Lynch, G., Kessler, M., Arai, A., \& Larson, J. (1990). The nature and causes of hippocampal long-term potentiation. In J. StormMathisen, J. Zimmer, \& O. P. Ottersen (Eds.), Progress in brain research: Vol. 83. Understanding the brain through the hippocampus (pp. 233-250). Amsterdam: Elsevier.

Madison, D. V., \& Schuman, E. M. (1991). LTP, post or pre? A look at the evidence for the locus of long-term potentiation. New Biologist, 3, 549-557.

McNaughton, B. L., Barnes, C. A., Rao, G., Baldwin, J., \& RasMUSSEN, M. (1986). Long-term enhancement of hippocampal synaptic transmission and the acquisition of spatial information. Journal of Neuroscience, 6, 563-571.

McNaughton, B. L., Douglas, R. M., \& Goddard, G. V. (1978). Synaptic enhancement in fascia dentata: Cooperativity among coactive afferents. Brain Research, 157, 277-293.

Moore, C. I., Browning, M. D., \& Rose, G. M. (1993). Hippocampal plasticity induced by primed burst, but not long-term potentiation, stimulation is impaired in area CAl of aged Fischer 344 rats. Hippocampus, 3, 57-66.

Moyer, J. R., JR., Deyo, R. A., \& Disterhoft, J. F. (1990). Hippocampectomy disrupts trace eye-blink conditioning in rabbits. Behavioral Neuroscience, 104, 243-252.

O'KeEFE, J., \& NADEL, L. (1978). The hippocampus as a cognitive map. Oxford: Oxford University Press.

Pacelli, G. J., SU, W., \& Kelso, S. R. (1989). Activity-induced depression of synaptic inhibition during LTP-inducing patterned stimulation. Brain Research, 486, 26-32.

PaCElli, G. J., Su, W., \& Kelso, S. R. (1991). Activity-induced decrease in early and late inhibitory synaptic conductances in hippocampus. Synapse, 7, 1-13.

Pavlides, C., Greenstein, Y. J., Grudman, M., \& Winson, J. (1988). Long-term potentiation in the dentate gyrus is induced preferentially on the positive phase of theta-rhythm. Brain Research, 439 383-387.

Pavlov, I. P. (1928). Conditioned reflexes. London: Oxford University Press.

Port, R. L., Beggs, A. L., \& Patterson, M. M. (1987). Hippocampal substrate of sensory associations. Physiology \& Behavior, 39, 643647.

ResCORLA, R. A. (1988a). Behavioral studies of Pavlovian conditioning. Annual Review of Neuroscience, 11, 329-352.

RESCORLA, R. A. (1988b). Pavlovian conditioning: It's not what you think it is. American Psychologist, 43, 151-160.

Rose, G. M., \& DUNwIDDIE, T. V. (1986). Induction of hippocampal long-term potentiation using physiologically patterned stimulation. Neuroscience Letters, 69, 244-248. 
Rudell, A. P., Fox, S. E., \& Ranck, J. B., JR. (1980). Hippocampal excitability phase-locked to the theta rhythm in walking rats. Experimental Neurology, 68, 87-96.

Sastry, B. R., Goh, J. W., \& Auyeung, A. (1986). Associative induction of posttetanic and long-term potentiation in CAl neurons of rat hippocampus. Science, 232, 988-990.

Shors, T. J., \& ThOMPson, R. F. (1992). Acute stress impairs (or induces) synaptic long-term potentiation (LTP) but does not affect paired-pulse facilitation in the stratum radiatum of rat hippocampus. Synapse, 11, 262-265.

Shulz, D., \& FregnaC, Y. (1992). Cellular analogs of visual cortical epigenesis. Il. Plasticity of binocular integration. Journal of Neuroscience, 12, 1301-1318.

Solomon, P. R., Vander SchaAf, E. R., Thompson, R. F., \& Weisz, D. J. (1986). Hippocampus and trace conditioning of the rabbit's classically conditioned nictitating membrane response. Behavioral Neuroscience, 100, 729-744.

Stanton, P. K., \& Sejnowski, T. J. (1989). Associative long-term depression in the hippocampus induced by Hebbian covariance. $\mathrm{Na}$ ture, 339, 215-218.

STAUBLI, U., \& LYNCH, G. (1987). Stable hippocampal long-term potentiation elicited by 'theta' pattern stimulation. Brain Research, 435, 227-234.

STAUBLI, U., \& OTAKY, N. (1994). Serotonin controls the magnitude of LTP induced by theta bursts via an action on NMDA-receptor-mediated responses. Brain Research, 643, 10-16.

TEYLER, T. J. (1991). A model of associative interactions mediated by N-methyl-D-aspartate activation. In W. C. Abraham, M. Coballis, \& K. G. White (Eds.), Memory mechanisms: A tribute to G. V. Goddard (pp. 27-43). Hillsdale, NJ: Erlbaum.

TEYLER, T. J., \& DiScenNa, P. (1987). Long-term potentiation. Annual Review of Neuroscience, 10,131-161.

VANDERWOLF, C. H. (1969). Hippocampal electrical activity and voluntary movement in the rat. Electroencephalography \& Clinical Neurophysiology, 26, 407-418.

VERTES, R. P. (1986). Brainstem modulation of the hippocampus. In R. L. Isaacson \& K. H. Pribram (Eds.), The hippocampus (Vol. 4, pp. 41-75). New York: Plenum.

Wigström, H., \& Gustafsson, B. (1986). Postsynaptic control of hippocampal long-term potentiation. Journal of Physiology, 81, 228-236.

Winson, J., \& ABzUG, C. (1977). Gating of neuronal transmission in the hippocampus: Efficacy of transmission varies with behavioral state. Science, 196, 1223-1225.
Winson, J., \& AbZUG, C. (1978). Neuronal transmission through hippocampal pathways dependent on behavior. Journal of Neurophysiology, 41, 716-732.

Young, S. L., Bohenek, D. L., \& Fanselow, M. S. (1994). NMDA processes mediate anterograde amnesia of contextual fear conditioning induced by hippocampal damage: Immunization against amnesia by context preexposure. Behavioral Neuroscience, 108, 19-29.

ZADOR, A., KoCH, C., \& Brown, T. H. (1990). Biophysical model of a Hebbian synapse. Proceedings of the National Academy of Sciences of the United States of America, 87, 6718-6722.

\section{NOTES}

1. Recent work has more fully described the processes that can lead to a lasting increase (LTP) or decrease (long-term depression, LTD) in excitability. In particular, the level of postsynaptic calcium concentrations is a critical variable in determining whether LTP or LTD will develop. A contemporary interpretation of the findings indicates that associative LTP stimulation and homo- and heterosynaptic LTP are all dependent on a surge of postsynaptic intracellular calcium concentrations and second messenger cascades downstream from the calcium signal (Artola \& Singer, 1993).

2 . The essential point of this commentary is that intense coactivation of high-frequency bursting and secondary activity may produce an endogenous form of LTP, and the effects need not be interpreted within the context of classical conditioning training conditions. We suggest that the theta rhythm is one possible mechanism whereby synapses may be primed to develop plasticity, but there are alternatives to theta-regulated plasticity. For example, 100-200-msec periods of bursting of cellular activity (sharp waves) occur in the hippocampus during non-theta states. Synchronous activation of the hippocampus by sharp waves and weak secondary activity may produce an endogenous form of associative LTP, which would also conform to the Hebb synapse concept of plasticity. This possibility has been considered by Buzsaki and colleagues (Buzsaki, 1989; Buzsaki, Chen, \& Gage, 1990). Similarly, an enhancement of transmission as a product of coactive afferents in extrahippocampal regions, such as the neocortex, may develop via Hebb synapse-type mechanisms (Ahissar et al., 1992; Fregnac, Shulz, Thorpe, \& Bienenstock, 1992; Shulz \& Fregnac, 1992).

(Manuscript received April 4, 1994; revision accepted for publication September $8,1994$. 